\title{
A stated preference valuation of the non- market benefits of pollination services in the UK
}

Article

Accepted Version

Breeze, T.D., Bailey, A.P., Potts, S.G. and Balcombe, K.G.. (2015) A stated preference valuation of the non-market benefits of pollination services in the UK. Ecological Economics, 111. pp. 76-85. ISSN 0921-8009 doi: https://doi.org/10.1016/j.ecolecon.2014.12.022 Available at https://centaur.reading.ac.uk/39678/

It is advisable to refer to the publisher's version if you intend to cite from the work. See Guidance on citing.

To link to this article DOI: http://dx.doi.org/10.1016/j.ecolecon.2014.12.022

Publisher: Elsevier

All outputs in CentAUR are protected by Intellectual Property Rights law, including copyright law. Copyright and IPR is retained by the creators or other copyright holders. Terms and conditions for use of this material are defined in the End User Agreement.

www.reading.ac.uk/centaur 
Central Archive at the University of Reading

Reading's research outputs online 


\title{
A Stated Preference Valuation of the Non-Market Benefits of Pollination Services in the UK
}

\author{
Breeze T.D. ${ }^{*}$, Bailey A.P. ${ }^{2}$, Potts S.G. ${ }^{1}$ and Balcombe K.G. ${ }^{3}$
}

\section{Abstract}

Using a choice experiment survey this study examines the UK public's willingness to pay to conserve insect pollinators in relation to the levels of two pollination service benefits: maintaining local produce supplies and the aesthetic benefits of diverse wildflower assemblages. Willingness to pay was estimated using a Bayesian mixed logit with two contrasting controls for attribute nonattendance, exclusion and shrinkage. The results suggest that the UK public have an extremely strong preference to avoid a status quo scenario where pollinator populations and pollination services decline. Total willingness to pay was high and did not significantly vary between the two pollination service outputs, producing a conservative total of $£ 379 \mathrm{M}$ over a sample of the tax-paying population of the UK, equivalent to $f 13.4$ per UK taxpayer. Using a basic production function approach, the marginal value of pollination services to these attributes is also extrapolated. The study discusses the implications of these findings and directions for related future research into the non-market value of pollination and other ecosystem services.

\section{Introduction}

Pollination, the transfer of pollen within and between flowers by insect vectors is a key ecological function facilitating reproduction in $78 \%$ of temperate flowering plants (Ollerton et al, 2011). These plants underpin the function of a range of ecosystem services, such as food crop production (Klein et al, 2007), soil quality, pest regulation (Sarrantonio, 2007) and improving landscape aesthetics (Lindemann-Matthies et al, 2010). At present, populations of both wild and managed pollinating insects within the UK have experienced substantial long-term declines (Potts et al, 2010; Carvalheiro et al, 2013), raising concerns about the stability of pollination services. As a regulatory, or intermediate, ecosystem service (Fischer et al, 2009), pollination has typically been valued as a component of the final benefits it provides (but see Allsopp et al, 2008). To date only the benefits to crop markets have been economically quantified to assess the value of production changes resulting from pollinations ervices to crops (e.g. Winfree et al, 2011). Unlike crop production, other final benefits of pollination services are not directly traded on markets and are often public (they are not owned by anyone exclusively) and non-excludable (people cannot be prevented from using them) (Cooke et al, 2009). Furthermore, there may be intrinsic values attached to the existence of pollinators (e.g. Mwebaze et al, 2010). As valuation is often used to underpin decision making, an exclusive focus on market benefits will neglect the broader impacts such decisions can have on wider stakeholders.

In order to redress the failure of markets to capture the benefits of non-market ecosystem services, economists have exploited a range of techniques, broadly categorized as revealed or stated preference methods. Revealed preference methods utilise existing market or experimental data to

\footnotetext{
${ }^{1}$ Centre for Agri Environmental Research, School of Agriculture, Policy and Development, University of Reading, Reading RG6 6AR, UK

${ }^{2}$ Department of Agriculture, School of Agriculture, Policy and Development, University of Reading

${ }^{3}$ Department of Food Economics and Marketing, School of Agriculture, Policy and Development, University of Reading
} 
estimate previously uncaptured benefits arising from ecosystem services (e.g. hedonic price models used to value the benefits of proximity to natural habitat on house prices; Hanley et al, 2007). Stated preference methods create a hypothetical market for environmental goods/services using a questionnaire or interview and ask respondents to state preferences for bundles of these goods/services. Costs attached to each bundle act as a price within the market, allowing estimation of respondent willingness to pay (WTP) to acquire or maintain the goods/services or their willingness to accept (WTA) compensation for their degradation of the goods/services if the costs are negative (Bateman et al, 2002), Stated preference allow a wide range of respondent factors to be modelled and compared and, unlike revealed preference techniques, are theoretically applicable to any ecosystem service (Hanley et al, 2007). Stated preference methods are based upon random utility models which assume that respondents are rational, self-serving utility maximisers who will express preferences that optimise their utility (Train, 2003). However, recent research has questioned these assumptions particularly for complex or unfamiliar goods and non-market goods. Subsequently, respondents may express lexicographic preferences, whereby they are unwilling to trade away any quantity of the good (Spash et al, 2009), and a number of biases which may obscure their true preferences. In particular when respondent awareness of the hypothetical nature of the study affects their response (hypothetical bias - e.g. Ivehammer, 2009) or where respondents avoid the risks of change even if they disapprove of the status quo (status quo bias - e.g. Boxall et al, 2009).

Stated preference surveys have been used to value a range of ecosystem services such as water quality (Zander and Stratton, 2010), recreation (Christie et al, 2007) and carbon sequestering (Mackerron et al, 2009). However, while final services, those with distinct end products that are directly consumed (Fischer et al, 2009), such as water quality, are more tangible and comprehensible to respondents who interact with them, intermediate services (those which enhance the production of end products), such as pollination, are often complex ecological concepts that the public find difficult to attribute value to. This can make valuations for ecosystem services difficult to elicit accurately with stated preference methods, due to the limited information available to respondents (Christie and Gibbons, 2011). This in turn increases the probability of respondents using decision simplifying strategies rather than fully considering all the information presented when expressing their preferences, further biasing the results (Meyerhoff and Liebe, 2009). Nonetheless, if carefully developed, stated preference studies can be used to capture aspects of ecosystem service benefits that are not included in existing valuation studies.

This study uses a choice experiment survey to assess respondents stated willingness to pay to conserve pollinators in order to prevent marginal losses in two previously unvalued final benefits of pollination services; the relative availability of UK grown produce and the diversity of aesthetic wildflowers. Presently, many key insect pollinated fruits are largely supplied by imports, while by contrast the UK is largely self-sufficient in wind-pollinated cereal crops (DEFRA, 2013). Consumer concerns regarding pollution, accountability and local economic impacts involved in food imports, have prompted a growing preference for locally produced foods (Chambers et al, 2007; Brown et al, 2009). As such, even if produce can be substituted with imports, loss of UK pollination services will reduce the availability of this preferential characteristic. Insect pollinated wildflowers can provide significant welfare benefits through enhancing the aesthetic quality of landscapes (Soini and Aakkula, 2007), habitats (Lindemann-Matthies, 2010; Junge et al, 2011) and road verges (Akbar et al, 2003). This aesthetic quality has substantial impacts on perceptions of landscapes (Natural England, 2009) and socio-cultural values associated with connectivity with nature (Kellert, 1996). Subsequently, destabilisation of plant-pollinator networks and the consequent loss of flowering 
species may diminish these benefits. Based upon this information, this study expects that respondent willingness to pay for pollinator conservation will rise in relation to the improving quality of these final goods.

\section{Methods}

\subsection{Experiment development and sampling}

This study evaluates respondent willingness to pay (WTP) to prevent losses in multiple pollination service end products using a choice experiment questionnaire. Choice experiment surveys present respondents with several bundles of goods and services with different attributes and ask them to indicate their preferred bundle. By attaching a cost to each choice and taking several choice sets per individual, choice experiments can be used to assess respondents' willingness to pay for marginal changes in each attribute rather than just the bundle as a whole.

\subsubsection{Design}

Typically, attributes are derived from policy, prior preferences elicited or scientific predictions, however quantitative relationships between pollinator populations, pollination service levels and end production are difficult to extrapolate in an easily comprehensible manner. The attributes selected for this choice experiment were aesthetic wildflower diversity, the relative availability of UK produce and price. Attribute levels were specified identically as changes in current levels compared to now from no change to $-30 \%$ in a linear incremental scale (Table 1 ) to elicit respondent willingness to pay to avoid losses in these pollination service benefits. These seemed sufficient to incentivise changes between options. The attributes were confirmed as suitable by a focus group, which considered the use of tax as payment vehicle (the hypothetical means by which payment would be collected) and the attribute levels to be comprehensible and believable. The cost attribute was framed as a possible future taxation to maintain realism (Ivehammar, 2009) and presented as both a monthly and annual increase. The cost attribute levels were modified after a 90 household pilot survey, so as to increase the variation in choices as most pilot respondents picked only the most expensive options.

Values ascribed to these attributes do not directly represent a valuation of pollinators. For simplicity, bees were chosen as a focal species because of their widely recognised importance as pollinators (Klein et al, 2007) and recent UK media coverage of declining populations. A measure of bee populations was considered as an attribute in the initial design however focus group discussions indicated difficulty in placing values on percentage changes in bee populations in relation to other attributes, indicating instead that it was the secure existence of the taxa and the services that they provide that mattered. Furthermore, such a variable could complicate the scenario by creating choice sets where bees decline but their services remain, which although plausible, many participants found hard to comprehend. Alternatively, other ecosystem functions may compensate for lost pollination services (Bommarco et al, 2013) however this introduces complex, multiple ecosystem service concepts into the scenario. The presence of a " do nothing" status quo option, whereby there is no additional effort is made to preserve bees in the UK, instead allows for some estimate of the intrinsic value respondents attach to the continued existence of bees by statistically analysing the impact of "non status-quo" options on WTP. 
Table 1 Choice attribute levels

\begin{tabular}{ll}
\hline Attribute & Levels \\
\hline $\begin{array}{l}\text { 1. UK grown fruit and vegetables available in } \\
\text { local shops compared to now }\end{array}$ & $-30 \% *,-20 \%,-10 \%$, Same as now \\
$\begin{array}{l}\text { 2. Variety of wildflowers in local green spaces } \\
\text { compared to now }\end{array}$ & $-30 \% *,-20 \%,-10 \%$, Same as now \\
3. Monthly tax increase to you & $£ 0^{*}, £ 0.5, £ 1, £ 1.5, £ 2, £ 2.5, £ 3, £ 3.5, £ 4$ \\
\hline * status quo attribute levels &
\end{tabular}

30 choice sets were initially developed with attribute balanced (i.e. attribute levels of each attribute appear across all choice sets the same number of times), D-optimal design algorithms, which aim to produce more statistically robust choice sets by minimising the standard error or standard deviations of the parameter estimates using initial assumptions about parameter signs and magnitudes. However, typical of D-optimal choice sets generated without adequate prior information, some of the resultant choice sets had little variation and often featured dominant options whereby one option was lower cost and offered higher benefits than the other, non-status quo option. Subsequently, choice sets were subjectively altered to eliminate dominant options and provide greater utility differences while maintaining attribute balance within the alternatives. Each respondent was presented with 6 choice sets, each with two unique alternatives to the status quo to reduce status quo bias by offering a range of alternatives (Rolfe and Bennett, 2009). The final questionnaire, designed following Dillman (2000), contained a cover letter providing respondents with information regarding pollination services provided by bees and the potential impacts of declines and outlined a scenario whereby taxation would be distributed by an apolitical government department to prevent and reverse declining bee populations in the UK.

To reduce hypothetical bias and incentivise truthful response, the sample was informed that, while presently hypothetical, the changes could be implemented by 2015 with enough popular support and would be applied across the UK. An A4 picture sheet was included containing 4 pictures of the same flower meadow featuring approximately 10 plant species (flowering and non-flowering), with a single species in each removed in all but the first, providing a visual representation of declining floral diversity which may otherwise be difficult for respondents to form preferences for (Bateman et al, 2009). Visual representations of changing levels of UK fruit and vegetables were considered but judged impractical as response to crop deletion may be influenced by respondent food preferences. Final questionnaire content was checked with a focus group for clarity and simplicity of language and relevance of questions.

\subsubsection{Respondent attitudes and attributes}

To capture the effect of respondent attitudes, environmental ethical stance and exposure to the choice attributes, the questionnaire asked respondents a series of questions to evaluate their attitudes and exposure towards the choice attributes, bee conservation and general concern, their ethical stance regarding conserving biodiversity, based upon an environmental-anthropogenic scale (Spash et al 2009) and whether they agreed or disagreed with funding bee conservation through taxes to better identify protest responses (Meyerhoff and Liebe, 2009). A final section contained a 
series of questions regarding respondent demographics, brackets of which were taken from the national census.

\subsubsection{Sampling}

Positive attitudes and willingness to pay for environmental goods/services are often increased by greater exposure and personal relevance of the service (Meyerhoff and Liebe, 2009) and decreased with further distance from the good/service (Bateman et al, 2006). Consequently, sampling was conducted over 3 counties in England; Kent, Lincolnshire and North Yorkshire based on the prominence of horticulture relative to arable crops reported in DEFRA (2013) to capture any bias caused by the significance insect pollinated crops to local agriculture.

To maximise the breadth of potential respondents given the budget available to the project, the questionnaire was designed as a postal based survey, allowing for more questions to be posed than phone or interview surveys can be answered at respondent discretion and can be more widely distributed (Bateman et al, 2002). By contrast, postal surveys innately suffer from self-selection bias towards retired and unemployed respondents (Dillman, 2000) and often have low response rates; necessitating large samples. In order to ensure an acceptable number of responses, a total of 2300 questionnaires were mailed to a purchased sample of English households, weighted by the number of households within each 4 digit postcode area in order to increase sample representativeness. Budget limitations prevented the sending of reminders which may have increased the response rate.

\subsection{Analysis}

\subsubsection{Choice analysis and Willingness to Pay}

Responses were analysed using a hierarchical Bayes Logit model which uses Bayesian processes to assess the probability of a respondent selecting a particular option based on the attributes of options they have been observed to make. Estimates of parameters are made with respect to the individual and for the mean and variance or the population as a whole; if price is included in the choices then the maximum price the bundle will be selected over all other bundles is the maximum WTP for the bundle. Utility, the quantitative benefit to personal wellbeing that a respondent receives from a bundle, is specified as:

$$
U_{n i}=V_{n i}+\varepsilon_{n i}
$$

Where $U_{n i}$ represents the utility of respondent $\mathrm{n}$ from choosing bundle $\mathrm{i}, V_{n i}$ represents deterministic utility, a vector of observed characteristics regarding the attributes of $n$ and $i$ and $\varepsilon_{n i}$ represents error, a vector of unobserved characteristics and stochastic variation in respondents which is assumed to have a Gumbell distribution. Respondents are assumed to maximise utility so that the choice probability $(P)$ of $n$ selecting $\mathrm{i}$, is:

$$
P_{n i}=P\left(U_{n i}>U_{n j} \forall j \neq i\right)
$$

In standard Mixed Logit, an individual's choice probability can therefore be estimated, based on observed characteristics. The deterministic component of utility is modelled as;

$$
V_{n i}=\beta_{n}^{s} x_{n i}
$$


202

203

204

205

206

207

208

209

210

211

212

213

214

215

216

217

218

219

220

221

222

223

224

225

226

227

228

229

230

231

232

233

234

235

236

where $B_{n}$ is a normally distributed vector of parameters for individual $\mathrm{n}$ with mean $\alpha$ and covariance matrix $\omega$

$$
\beta_{n} \sim N(\alpha, \omega)
$$

$x_{n i}$ represent the attributes levels of bundle i presented to respondent $\mathrm{n}$. Subsequently, the probability that respondent $\mathrm{n}$ chooses bundle i becomes:

$$
P_{n i}=\left(\frac{e^{\beta_{n}^{r} x_{n i}}}{\sum_{j} e^{\beta_{n}^{I} x_{n j}}}\right)
$$

Where $x_{n i}$ are attributes within $V_{n i}$. The marginal utilities for each attribute are the elements of $\beta_{n}^{\prime}$ within the standard Mixed Logit. Typically normal or log-normal (where the sign of the parameter is known) and can be specified differently for each element of $\beta_{n}^{\prime}$.

The model utilised in this study estimates $\beta_{n}^{s}$ using 500,000 Monte-Carlo Markov Chain (MCMC) draws, retaining every $50^{\text {th }}$ draw to compile into $\beta_{n}^{z}$ in order to decrease the co-dependence of the sampled values. As estimates of $\beta_{n}^{\prime}$ should be independent of starting points for the MCMC estimation, an additional 50,000 draws were taken and discarded prior to the main draws. Model priors for $\alpha$ and $\omega$ were estimated using relatively diffuse normal priors for $\alpha$ and Wishart prior $\omega$ as specified in Train (2003 -Chap. 12). Analysis was undertaken in both preference space, where the distribution of marginal utility is estimated and the rate of marginal utility substitution between attributes calculated on this basis, and WTP space, which estimates the rate of marginal utility substitution directly and may produce greater stability in WTP estimates (Balcombe et al, 2009). Preliminary analysis of the data indicated that model fit was best when evaluated in preference space rather than WTP space. As preference space estimates can be prone to bias from extreme values, median attribute coefficients and WTP estimates were used in place of mean estimates.

Respondent descriptors were incorporated into the model on the basis of research interest and a priori expectation regarding their significance. Age and income categories and attitudes towards taxation were included as continuous variables. Dummy variables were used to account for income refusal and the 3 counties with North Yorkshire used as a reference. The influence of the level of urbanisation respondents encountered was assessed on a 1 (urban) to 3 (rural) gradiant with those indicating "other" occupancy placed in category 2. Other demographic and attitudinal variables were evaluated separately to avoid over-parameterisation (see Appendix 1).

\subsubsection{Attribute non-attendance}

Attribute non-attendance (ANA), whereby respondents ignore one or several attributes of a choice in making their decisions, is often handled by setting the marginal utility of the attribute to zero for non-attendant respondents (e.g. Balcombe et al. 2011) or removing the respondent entirely in the case of non-attendance on the cost attribute (e.g. Zander and Stratton, 2010). These approaches assume that respondents either have no utility, and thus zero WTP, attached to ignored attributes or are misreporting their preferences (Hensher, 2006). In actuality, respondent decisions may be dominated by the other attributes or their preferences towards an attribute may be simply polarised towards or against extreme values. Alternatively, it can be assumed that non-attendant respondents have a lower marginal utility value for the attribute than attendees. This can be modelled by incorporating a shrinkage parameter which is assumed to lie on a normally distributed 0-1 scale. Consequently if a respondent is non-attendant on an attribute $(k)$ their marginal utility for 
that attribute becomes: $\beta_{n k}^{*}=$ shrinkage $\times \beta_{n k}$. Initial work suggests that this ANA shrinkage approach outperforms other methods of treating ANA (Kehlbacher et al, 2013). The approach used here posits a distribution for the marginal utilities dependant on non-attendance data, making no stronger assumptions about the nature of independence than a latent variable approach.

\subsubsection{Extrapolation}

As postal surveys tend to have low response rates and are vulnerable to self-selection biases, whereby only those interested in the questionnaire respond, extrapolating WTP estimates to the total UK working population may overestimate total value. As such, two extrapolations were conducted for each model, one assuming that all $28.2 \mathrm{~m}$ working adults aged 18-64 in the UK (ONS, 2011) would be willing to pay (Upper Bound) while another assumes that the percentage of the sample that did not respond had no WTP for pollination service conservation (Lower Bound).

\subsubsection{Estimating the value of pollination services}

Typically, the value of pollination services to crops is estimated using a basic production function, by multiplying each crops insect pollinator dependence ratio by the total market price of the crop (see e.g. Gallai et al, 2009). This study uses a similar methodology to estimate the value of pollination services to the non-market benefits in the questionnaire; estimating the proportion of each benefit that arises from pollination services.

For UK produce (fruits and vegetables), this was based on the proportion of UK domestic crop consumption that would be lost without pollination services. The total volume of UK production in 2010 for the domestic market was derived from DEFRA $(2013,2012)$. As only crop produce produced and sold in the UK was valued, the production of each crop was multiplied by 1 - the \% of crop exported. Where specific crop data was not available, crop groups (fruit or vegetables) was used as a proxy. The proportion of domestic production lost was estimated by multiplying the volume of production by their insect pollination dependence ratios from Smith et al (2011) and Gallai et al (2009), resulting in an estimate of as $~ 12 \%$ of domestic consumption arising from pollination services. Assuming a linear relationship between pollinator abundance and services (Garibaldi et al, 2013), this means that a 1\% decline in insect pollinator populations would produce a $0.12 \%$ decline in the availability of UK fruit and vegetables.

Ollerton et al (2011) estimate that $~ 78 \%$ of temperate flowering plants are pollinated by insects, however it is not yet known what proportion of these depend exclusively upon insect pollination (or specifically pollination by bees), or if this reflects the pollinator dependence of UK flora. Nonetheless, if it is assumed that this ratio is correct and that at least half of these species are entirely dependent on insect pollination this means that a $100 \%$ loss of insect pollinators would produce a $39 \%$ decline in wildflower diversity. The loss of $1 \%$ of insect pollinators would therefore be expected to produce a $0.39 \%$ decline in wild plant diversity, assuming again a linear relationship between pollinator abundance and services.

\section{Results}

\subsection{Response}

In total 312 questionnaires (14\%) were returned, of which 278 were completed sufficiently to be included in analyses, resulting in 1668 choice observations. Those respondents that did not 
complete a choice set were assumed to have answered "don't know". The response rate was approximately equal across counties. Typical of postal questionnaires, a high proportion of respondents were in the higher age brackets with $76.3 \%$ of respondents being aged 45 or over and only $7.2 \%$ under 30 . Most respondents currently live in market or commuter towns (44\%) and rural areas (33\%) with only $15 \%$ of respondents residing in urban areas although the proportion of respondents growing up in each category was approximately equal. Respondent income was largely in the lower income categories although $\sim 11 \%$ indicated annual income of $>£ 75 \mathrm{k}$. Approximately $15 \%$ of respondents stated that they were non attendant on either UK produce or wildflower diversity while $46 \%$ were non-attendant on taxation.

Respondent awareness of UK bee declines was very high (88\%). More than half of respondents (68\%) indicated that they grew their own fruit and vegetables and $22 \%$ were members of a relevant Non-Government Organisation. Only 1\% kept bees and $8 \%$ had work experience in a relevant field. Attitudes towards bee conservation were positive with $97 \%$ agreeing with the statement that bee conservation was important and <1\% disagreeing. Approximately $75 \%$ agreed with the statement that environmental protection would require funding through taxation verses $9 \%$ disagreeing. Attitudes towards the attributes were also generally strong and positive, although only $18 \%$ regularly visit green spaces. Respondent ethical stances were more mixed with $~ 70 \%$ of respondents indicating equitable (humans and other species have equal rights) or anthropocentric (humans have more rights than other species) attitudes.

Pearson's Correlation analysis indicates highly significant relations between several respondent attitude and demographic parameters (Appendix 2). In particular, general environmental concern correlates very strongly with positive attitudes towards the attributes and bee conservation, acceptance of taxation as a means of funding environmental protection and environmentalist ethical stances. Acceptance of environmental taxation positively correlated with respondent qualification and income. Attitudes towards bee conservation correlated positively with respondent age and negatively with number of dependants.

\subsection{Choice Probability Parameters and Willingness to Pay}

In both the attribute non-attendance (ANA) shrinkage (Model 1) and Cost Attendees only (Model 2) models, all choice attributes had the expected signs for both preferences and WTP estimates (Table 2) (£175.88/respondent/year vs $£ 95.83 /$ respondent/year) with attribute specific WTP approximately twice that of Model 1. As the questionnaire offered bundles with varying degrees of loss of attributes, all attributes entered the model as negative values, including cost reflecting its nature as a negative impact upon respondent utility. In Model 1 ANA shrinkage was estimated at 0.44 (s.d. 0.07), indicating that attenders derived approximately twice as much utility from these attributes as non-attenders. In both models, the alternative specific constant (ASC) parameter, representing willingness to pay to avoid the status quo situation, was negative and produced high WTP values indicating that respondents strongly rejected the "do nothing" status quo. There was little difference in WTP for a $1 \%$ increase between UK produce or wildflower diversity in either model, suggesting that respondents were largely concerned with avoiding the status quo. 
Table 2 Model coefficients and WTP for choice attributes (standard deviations in brackets)

\begin{tabular}{|c|c|c|c|c|}
\hline & \multicolumn{2}{|c|}{ Model 1} & \multicolumn{2}{|c|}{ Model 2} \\
\hline Attribute & Choice Probability & WTP & Choice Probability & WTP \\
\hline \multirow[t]{2}{*}{ ASC } & $-1.04 *$ & $-f 73.4$ & $-1.195 *$ & $-f 46.3$ \\
\hline & (1.16) & (5692.1) & (1.44) & (7861) \\
\hline \multirow[t]{2}{*}{ UKP } & $0.2757^{*}$ & f1.79 & 0.2361 & $£ 0.81$ \\
\hline & $(0.29)$ & (1066.9) & $(0.31)$ & (1514.8) \\
\hline \multirow[t]{2}{*}{ WDF } & $0.2335^{*}$ & $£ 1.63$ & $0.1751^{*}$ & $£ 0.84$ \\
\hline & $(0.34)$ & (1047.9) & $(0.38)$ & (1182.4) \\
\hline \multirow[t]{2}{*}{ CST } & $0.9512 *$ & & 1.2856 & \\
\hline & (1.53) & & (2.51) & \\
\hline \multicolumn{2}{|c|}{ Total WTP/Respondent $^{1}$} & $f 175.88$ & & f95.83 \\
\hline \multicolumn{2}{|c|}{ ANA Shrinkage Parameter } & 0.44 & & \\
\hline \multirow{2}{*}{\multicolumn{2}{|c|}{$\begin{array}{l}\text { Maximum Simulated Log-Likelihood } \\
\text { Pesudo } \mathrm{R}^{2}\end{array}$}} & -811.21 & & -515.19 \\
\hline & & 0.72 & & 0.49 \\
\hline \multicolumn{2}{|c|}{ Number of Respondents } & 278 & & 151 \\
\hline
\end{tabular}

Against expectations, most respondent descriptors proved non-significant ${ }^{4}$ upon selecting non status-quo alternatives, particularly in Model 2 (Table 3). As expected, respondents that disagreed with paying for taxes to provide environmental protection were significantly more likely to accept the status quo in both models. In Model 1 these respondents were significantly less likely to accept options which produced greater levels of wildflowers and UK produce but not less likely to select options which had a greater cost. By contrast, in Model 2, strong tax avoidance attitudes only significantly reduce the probability of respondents selecting higher cost options. In both models, respondents from Lincolnshire were significantly more likely to select higher cost options, regardless of other attributes, indicating a greater WTP for bee conservation. In common with past research (e.g. Broberg and Brännlund, 2009), Model 2 demonstrates differences between urban and rural respondents with rural respondents holding lower WTP than urban residents. Finally, in Model 1, higher respondent income marginally increased the likelihood of selecting options with greater availability of UK produce.

\footnotetext{
${ }^{4}$ The term significant is used here to signify that the standard deviations were more than twice that of the means as Bayesian analysis does not technically allow for tests of significance.
} 
Table 3 Extrapolated upper bound and lower bound population total WTP values

\begin{tabular}{lllll}
\hline & \multicolumn{2}{c}{ Upper Bound } & \multicolumn{2}{c}{ Lower Bound } \\
& Model A & Model B & Model A & Model B \\
\hline All Attributes & $£ 4.96 \mathrm{bn}$ & $£ 2.70 \mathrm{bn}$ & $£ 695 \mathrm{M}$ & $£ 379 \mathrm{M}$ \\
ASC & $£ 2.07 \mathrm{bn}$ & $£ 1.30 \mathrm{bn}$ & $£ 290 \mathrm{M}$ & $£ 183 \mathrm{M}$ \\
UKP & $£ 1.5 \mathrm{bn}$ & $£ 685 \mathrm{M}$ & $£ 212 \mathrm{M}$ & $£ 96 \mathrm{M}$ \\
WDF & $£ 1.3 \mathrm{bn}$ & $£ 711 \mathrm{M}$ & $£ 193 \mathrm{M}$ & $£ 100 \mathrm{M}$ \\
\hline
\end{tabular}

Key: ASC = Alternative specific constant; UKP = UK produce availability retained (in \%); WDF = Wildflower diversity retained (in \%); CST = Cost in $£ /$ year. Total population = WTP values extrapolated to all 28.2m UK working adults aged 18-64.

Response Rate $=$ WTP values are extrapolated to $3.9 \mathrm{~m}$ members $(14 \%)$ of the working population, reflecting the response rate of the questionnaire itself. Model A considers ANA using an ANA shrinkage method. Model B considers ANA by removing non-attenders from the sample.

Upper bound extrapolations of the WTP values, which assume all $28.2 \mathrm{M}$ working adults in the UK would be willing to pay the values reported in table 2, result in an extremely high total value of $£ 4.96 \mathrm{bn}$ and $£ 2.70 \mathrm{bn}$ for Models 1 and 2 respectively (Table 4). However, this value is likely to be exaggerated by stronger response rate from those willing to pay than those who are not, a lower bound analysis was conducted which assumes that a proportion of UK working adults equal to the response rate (14\% - 3.94M adults) are willing to pay these values. This resulted in much more conservative extrapolations of $£ 695 \mathrm{M}-£ 379 \mathrm{M}$ for Models 1 and 2 respectively; equivalent to an annual tax increase of $£ 24.6$ and $£ 13.4$ per UK taxpayer.

Table 4 Coefficients for mean effects for respondent descriptors (standard deviation in brackets)

\begin{tabular}{lllllllll}
\hline & \multicolumn{3}{c}{ Model 1 } & \multicolumn{5}{c}{ Model 2 } \\
\hline & ASC & UK Produce & Flowers & Tax & ASC & UK Produce & Flowers & Tax \\
\hline$\alpha$ & $-1.40^{*}$ & $0.27^{*}$ & $0.51^{*}$ & $2.6^{*}$ & $-3.24^{*}$ & 0.26 & $0.50^{*}$ & 2.88 \\
Age & $(0.58)$ & $(0.13)$ & $(0.15)$ & $(1.46)$ & $(1.66)$ & $(0.2)$ & $(0.24)$ & $(2.04)$ \\
& 0.01 & 0.02 & 0.01 & -0.09 & -0.15 & 0.02 & 0.02 & -0.08 \\
Income & $(0.08)$ & $(0.02)$ & $(0.02)$ & $(0.23)$ & $(0.24)$ & $(0.03)$ & $(0.03)$ & $(0.3)$ \\
& 0.01 & $0.03^{*}$ & 0.00 & 0.23 & 0.08 & 0.01 & -0.01 & 0.07 \\
Income Refused & $(0.07)$ & $(0.02)$ & $(0.02)$ & $(0.2)$ & $(0.19)$ & $(0.03)$ & $(0.03)$ & $(0.26)$ \\
& 0.22 & 0.02 & -0.09 & -0.73 & 0.98 & -0.04 & -0.16 & -1.24 \\
Kent & $(0.29)$ & $(0.08)$ & $(0.09)$ & $(0.77)$ & $(0.84)$ & $(0.12)$ & $(0.14)$ & $(0.99)$ \\
& -0.26 & -0.03 & -0.07 & -1.05 & -0.67 & -0.04 & -0.08 & -1.35 \\
Lincolnshire & $(0.22)$ & $(0.06)$ & $(0.07)$ & $(0.64)$ & $(0.69)$ & $(0.11)$ & $(0.12)$ & $(1.09)$ \\
& -0.18 & -0.01 & -0.13 & $-1.87^{*}$ & -0.32 & -0.08 & -0.16 & $-2.74^{*}$ \\
Urban/Rural & $(0.27)$ & $(0.07)$ & $(0.08)$ & $(0.82)$ & $(0.8)$ & $(0.12)$ & $(0.15)$ & $(1.32)$ \\
& -0.10 & 0.02 & -0.01 & -0.52 & -0.09 & 0.002 & -0.06 & $-0.97^{*}$ \\
Tax Attitudes & $(0.13)$ & $(0.03)$ & $(0.04)$ & $(0.39)$ & $(0.38)$ & $(0.06)$ & $(0.06)$ & $(0.52)$ \\
& $0.36^{*}$ & $-0.07^{*}$ & $-0.10^{*}$ & 0.39 & $0.9^{*}$ & -0.03 & -0.05 & $0.94^{*}$ \\
& $(0.13)$ & $(0.03)$ & $(0.03)$ & $(0.33)$ & $(0.42)$ & $(0.05)$ & $(0.05)$ & $(0.44)$ \\
\hline
\end{tabular}

Key $\alpha=$ constant/intercept. Age = Age category as per the 2001 UK census. Income $=$ Income categories as per the 2001 UK census. Income refused = dummy variable where 1 indicates a refusal to state income. Kent = Dummy variable denoting respondent from Kent. Lincolnshire $=$ Dummy variable denoting respondent from Lincolnshire. Urban/Rural = continuous variable indicating urban or rural dwelling. Tax Attitudes = continuous variable indicating increasing aversion to tax. ${ }^{*}=$ significant effect based on Pseudo t-values approaching 2

The marginal value of pollination services to these end benefits was estimated by multiplying the WTP for each attribute by the proportion of the attribute that can be attributed to pollination services ( $12 \%$ and $39 \%$ respectively) (Table 5). Multiplying the values per $1 \%$ of service by 30 , representing the maintenance of all services under risk in the scenario presented, results in a 
total WTP to fully maintain these end benefits of $£ 25.5 /$ person under model 1 and $f 12.6 /$ person under model 2. Extrapolated using the upper and lower bound estimation, this indicated pollination services have a value of between $f 50 \mathrm{M}$ to $f 720 \mathrm{M}$ to these non-market benefits.

Table 5 Estimated WTP values for pollination services

\begin{tabular}{l|l|ll}
\hline & \multicolumn{2}{l}{ Model 1 } & Model 2 \\
\hline Willingness to Pay to maintain 1\% & UK Produce & $f 1.79$ & $f 0.81$ \\
of the attribute & Wildflower Diversity & $£ 1.63$ & $f 0.84$ \\
\% change from a 1\% loss of & UK Produce & 0.12 & 0.12 \\
pollinators & Wildflower Diversity & 0.39 & 0.39 \\
Estimated WTP for a 1\% & UK Produce & $£ 0.21$ & $£ 0.10$ \\
maintenance of pollination service & Wildflower Diversity & $£ 0.64$ & $£ 0.33$ \\
Estimated WTP to maintain 100\% & UK Produce & $£ 21.48$ & $£ 9.72$ \\
of services & Wildflower Diversity & $£ 63.57$ & $£ 32.76$ \\
Estimated Total WTP & Upper Bound & $£ 720 \mathrm{M}$ & $£ 350 \mathrm{M}$ \\
& Lower Bound & $£ 101 \mathrm{M}$ & $£ 50 \mathrm{M}$ \\
\hline
\end{tabular}

Key: Upper Bound $=$ the sum of WTP to maintain $100 \%$ of pollination services extrapolated to the entire tax paying population of the UK. Lower Bound = the sum of WTP to maintain $100 \%$ of pollination services extrapolated to $14 \%$ of the tax paying population of the UK. Model $1=$ Analysis including Attribute non-attendance shrinkage Model $2=$ analysis made by removing respondents that did not attend cost.

\section{Discussion}

\subsection{Model Outputs}

This study has demonstrated that respondents possess a high willingness to pay for avoiding the loss of the non-market end benefits of pollination services. However the results are likely to be upwardly influenced by a number of biases and respondent factors, potentially exaggerating final estimates. Especially strong status quo aversion was prevalent throughout the responsive population, producing very high Willingness to Pay (WTP) values for the alternative specific constant (the willingness to pay to avoid the status quo) in both the models estimated. This may be the product of high existence values, (the innate utility respondents attach to knowing that a good or service exists) for both bees and the end products of pollination services used as attributes. This is supported by the strong similarities between the alternative specific constant determined using attribute non-attendance shrinkage and the findings of Mwebaze et al (2010) which estimate a total WTP for bee conservation alone of $£ 71.24 /$ respondent. This study made some reference towards the benefits of pollination services but did not describe them in detail. As such the values reported in this study may represent value added to this existence value due to more explicit information on the benefits of pollination services. Alternatively, the findings could be interpreted as a disambiguation of the WTP reported by Mwebaze et al (2010) with some, moderate increase in WTP due to differing information. Respondent's highly positive attitudes towards bees and the products of pollination further substantiate this notion. Another possibility is that respondents may have held an anti-status quo bias - completely rejecting the status quo situation of pollinator losses. This may reflect lexicographic preferences against the status quo, where respondents found the do nothing scenario totally unacceptable. Alternatively the costs of action may not have disincentivised payments enough to favour the no-cost status quo, especially as no other benefits of accepting the status quo were presented (e.g. Hynes et al, 2010). This is supported by the lack of significant income effects upon either the alternative specific constant or the tax attribute in response probability. 
Although the high proportion of respondents were of retired age (>60years) may causean upward bias in WTP as these respondents would not have to pay any tax imposed, no significant effect of age category was found for either alternative specific constant or the cost attribute. Hypothetical bias, where respondents exaggerate their willingness to pay because of the hypothetical nature of the questionnaire, may also explain the low significance of the cost attributes on respondent choices, high tax non-attendance among respondents and the number of respondents who indicated objections to taxation still expressed preferences for conservation options. Future research in this area may benefit from the introduction of cheap talk devices in choice experiment scenario (Carlsson et al, 2005), which explicitly explain some or all of the survey mechanics that may cause bias, such as overstating preferences, to deepen respondents consideration of actual preferences (but see Henscher, 2010).

Of the two approaches to handling attribute non-attendance; using a shrinkage factor (Model 1 ) was found to produce significantly greater WTP estimates than removing respondents that expressed non-attendance for costs (Model 2 - Table2). This arises because Model 1 indicates that cost had approximately half the effect on utility of non-attenders compared to attenders, resulting in non-attenders maintaining a substantial influence on WTP estimates. Under both models, respondent WTP for each of the insect pollinated benefit attributes was very similar. This may result from similar levels of exposure to these attributes, resulting in stronger (Christie and Gibbons, 2011), more stable preferences (Bateman et al, 2008). Another possible means of controlling for the effects of attribute non-attendance is the use of Bayesian stochastic attribute selection (Scarpa et al, 2009), or by asking respondents whether they were non attendant in each choice set (Scarpa et al, 2010). These methodologies however are limited by their respective applicability of Latent class models and increased question complexity respectively. These findings highlight the importance of considering attribute non-attendance in choice modelling, particularly if the findings are to be extrapolated beyond the sample population.

The findings of this study also raise questions regarding the extrapolation of choice experiment results towards total populations. National WTP values ranging from $f 4.96 \mathrm{bn}-\mathrm{f} 695 \mathrm{M}$ and from $f 2.7 \mathrm{bn}-\mathrm{f} 379 \mathrm{M}$ under Models 1 and 2 respectively based on the extrapolation method involved. Contrarily, this lower bound estimate assumes that non-respondents have no WTP where they may in fact simply be unwilling or unable to respond, particularly as reminders were not sent to prompt further response. Typically national scale extrapolations of stated preference value have assumed that non-respondents hold similar WTP values to respondents. However the lower bound estimates in this study, whereby the values were only assumed to apply to a percentage of the population equal to the response rate, illustrate not only the disparity in estimates, particularly where WTP is high, but the resultant tax increase required. A deeper examination of the means to extrapolate WTP from stated preference studies could make such studies more applicable to policy. Ideally, this should be accompanied with further analysis of the trade-offs in welfare for those unwilling to pay for the new policy.

\subsection{Valuing Pollination Services}

Most critically, the results provide a basic first indication of the value of pollination services to final goods and services beyond crop production. The values estimated ( $£ 25.5-£ 12.6 /$ person) strongly hinge on the assumption that pollination responds linearly to pollinator abundance within the landscape. Although this has been broadly demonstrated for insect pollinated crops (Garibaldi et al, 2013) the shape of this relationship within wild plant networks is presently unknown and it is 
likely to plateau after a certain level of pollen deposition. Furthermore it does not include the potential additive or multiplicative effects of pollinator diversity (e.g. Greenleaf and Kremen, 2006). However these estimates remain useful as an initial valuation of the value of pollination services to non-market public benefits which have been hereto overlooked by valuation studies. The high value placed on the diversity of aesthetic wildflowers in particular highlights the potential value of pollination services outside of crop production. Furthermore, they do not capture the value added to consumers outside of the landscape that benefit from the availability of preferred nationally sourced produce.

\subsection{Implications}

Strong respondent concern about the pollinator declines and high WTP both for the end benefits of pollination services and the avoidance of the status quo suggest there may be scope for enhancing public participation in pollinator conservation, beyond perhaps, that of monetary contribution. For instance voluntary monitoring and recording schemes, have yielded substantial information on urban bumblebee nesting (Osborne et al, 2008), distribution (Kadoya et al, 2009) and population dynamics (Kawk, 1997). At a larger scale such public participation in wildlife monitoring schemes can also provide significant primary data for use in future research (e.g. Carvalheiro et al, 2013). Although further research will be required to translate the preferences recorded within this study into measures of public willingness to participate in such efforts, the findings nonetheless provide compelling evidence that the public are likely to be supportive of efforts and public spending on pollinator conservation.

Most significantly, the findings highlight the importance of considering other benefits from pollination services beyond crops. However, the capacity of this study to accurately elicit these values is limited both by the extent of the survey and by a number of economic and ecological knowledge gaps. Although quantities of produce available for home production are broadly known, an unknown proportion of this will be used in processing rather than sold fresh. Consequently it is not possible to accurately estimate the proportion of UK produce for domestic consumption. This can be improved upon with a more detailed analysis of supply chains of insect pollinated produce within the UK, facilitating broader economic understanding of the vulnerability of UK consumers to losing domestic supplies. The relative importance of produce origin compared to price or quality also remains unquantified. As such, it is not possible to assess the impacts of other trade-offs that may result from a loss of pollination services; if consumer welfare increases more from a lower price than consuming local produce then lower cost imports may increase welfare overall. While recent studies have begun to draw generalised trends in the impacts of pollinator communities on service provision (e.g. Garibaldi et al, 2013) the relationships between pollinator abundance and diversity has not been similarly generalised. Furthermore, despite extensive assessment of the flora of the UK, to date there has not been an assessment of how many UK plant species benefit from pollination services to varying extents (unlike crops - Klein et al, 2007). Subsequently it is not possible to accurately determine how wild plant communities will react to a loss of pollinators despite evidence of parallel declines between pollinators and wild plants within the UK (Carvalheiro et al, 2013). Similarly, it is not know to what extent members of the UK public value different aspects of floral diversity within a viable landscape; for instance people may have a preference for orderly arrangements of flowers or a range of visually distinct species (Lindemann-Matthies et al, 2010). Understanding this would allow for a more accurate assessment of the aesthetic value of floral diversity and the subsequent contribution that pollination does or can make to it. 
The findings of this study demonstrate that respondents have a very strong preference for situations that avoid the status quo scenario of pollinator and pollination service losses and are prepared to pay for these accordingly. These preferences are equally strong between the two benefits of pollination services, wildflower diversity and availability of UK produce, presented to respondents and were perhaps surprisingly not strongly influenced by respondent age, income or ethical stance. Although respondents who protested against tax were less likely to accept an alternative scenario they were nonetheless in favour of preserving pollination services and nearly all respondents felt that preserving pollinator populations was an important issue. With many drivers of pollination service decline set to continue, further research into public preferences for pollinator conservation will likely yield beneficial insights into both raising public support for pollinator conservation and the quantitative impacts of pollination services upon human welfare. A stronger understanding of public preferences for attributes of the produce they consume and the landscapes they view will enhance the accuracy and interpretation of these findings.

\section{References}

499

Akbar K.F., Hale W.H.G. and Headley A.D. (2003) Assessment of scenic beauty of the roadside vegetation in northern England; Landscape and Urban Planning 63, 139-144

Allsopp M.H., de Lange W.J. and Veldtman R. (2008) Valuing Insect Pollination Services with Cost of Replacement; PLoS One 3 0.1371/journal.pone.0003128

Balcombe K., Burton M., Rigby D. (2011) Skew and attribute non-attendance within the Bayesian mixed Logit model, Journal of Environmental Economics and Management 62, 446-461

Bateman I., Carson R.T., Day B., Hanemann M., Hanley N., Hett T. Jones-Lee M., Loomes G., Mourato

506 S. Ozdemiroglu E., Pearce D.W., Sudgen and Swanson J. (2002) Economic Valuation with Stated Preference Techniques: A Manual; Edward Elgar Press; Cheltenham

Bateman, I.J., Day, B.H., Georgiou, S. and Lake, I. (2006) The Aggregation of Environmental Benefit Values: Welfare Measures. Distance Decay and Total WTP; Ecological Economics 60 (2), 450-460.

510 Bateman I., Burgess D., Hutchinson W.G. and Matthews D.I. (2008) Learning design contingent 511 valuation (LDCV): NOAA guidelines, preference learning and coherent arbitrariness; Journal of 512 Environmental Economics and Management 55, 127-141

513 Bateman I., Day B.H., Jones A.P. and Jude S. (2009) Reducing gain-loss asymmetry: A virtual reality 514 choice experiment valuing land use change; Journal of Environmental Economics and Management $515 \quad 58,106-118$

516 Boxall P., Adamowicz W.L. and Moon A. (2009) Complexity in choice experiments: choice of the 517 status quo alternative and implications for welfare measurement; The Australian Journal of 518 Agricultural and Resource Economics 53, 503-519

519 Broberg T. and Brännlund R. (2008) On the Value of Large Predators in Sweden: A Regional Stratified 520 Contingent Valuation Analysis; Journal of Environmental Management 88, 1066-1077 
521 Brown E., Dury S. and Holdsworth M. (2009) Motivations of consumers that use local, organic fruit

522 and vegetable box schemes in Central England and Southern France; Appetite 53, 183-188

523 Carlsson F., Frykblom P and Lagerkvist C.J. (2005) Using cheap talk as a test of validity in choice

524 experiments; Economics Letters 89, 147-152

525 Carvalheiro L.G., Kunin W.G., Keil P., Aguirre-Gutierrez J., Ellis W.E., Fox R., Groom Q., Hennekens S., 526 Landuyt W., Meas D., de Meutter F.V., Michez D., Rasmont P., Ode B., Potts S.G., Reemer M.,

527 Roberts S.P.M., Schaminee J., WallisDeVires M.F. and Biesmeijer J.C. (2013) Species Richness

528 Declines and Biotic Homogenisation have Slowed Down for NW-European Pollinators and Plants;

529 Ecol. Lett. 16, 870-878

530 Chambers S. Lobb A., Butler L., Harvey K. and Traill W.B. (2007) Local, national and imported foods: A 531 qualitative study; Appetite 49, 208-213

532 Christie M. and Gibbons J. (2011) The effect of individual 'ability to choose' (scale heterogeneity) on 533 the valuation of environmental goods; Ecological Economics 70, 2250-2257

534 Christie M., Hanley N. and Hynes S. (2007) Valuing enhancements to forest recreation using choice 535 experiment and contingent behaviour methods; Journal of Forest Economics 13, 75-102

536 Cooke I., Queenborough S.A., Mattison E.H.A., Bailey A.P., Sandars D.L., Graves A.R., Morris J., 537 Atkinson P.W., Trawick P., Freckleton R.P., Watkinson A.R. and Sutherland W.J. (2009) Integrating 538 socio-economics and ecology: a taxonomy of quantitative methods and a review of their use in agro539 ecology; Journal of Applied Ecology 46, 269-277

540 DEFRA (2012) Farming statistics: land use, livestock populations and agricultural workforce at 1 June 5412012 - UK; https://www.gov.uk/government/publications/farming-statistics-land-use-livestock-

542 populations-and-agricultural-workforce-at-1-june-2012-uk last updated 18/03/11

543 DEFRA (2013) Agriculture in the UK 2012 https://www.gov.uk/government/statistical-data-

544 sets/agriculture-in-the-united-kingdom last updated 25/07/13

545 Dillman D. (2000) Mail and Internet Surveys - The Tailored Design Method; Wiley, London

546 Fisher B, Turner R.K. and Morling P. (2009) Defining and Classifying Ecosystem Services for Decision

547 Making; Ecological Economics 68, 634-653

548 Gallai N., Salles J. M., Settele J. and Vaissiere B. E. (2009) Economic Valuation of the Vulnerability of 549 World Agriculture Confronted with Pollinator Decline; Ecol. Econ. 68, 810-821

550 Garibaldi L.A., Steffan-Dewenter I., Winfree R., Aizen M.A., Bommarco R., Cunningham S.A., Kremen 551 C., Carvalheiro L.G., Harder L.D., Afik O., Bartomeus I., Benjamin F., Boreux V., Cariveau D., Chacoff 552 N.P., Dudenhöffer J.H., Freitas B.M., Ghazoul J., Greenleaf S., Hipólito J., Holzschuh A., Howlett B., 553 Isaacs R., Javorek S.K., Kennedy C.M., Krewenka K.M., Krishnan S., Mandelik Y., Mayfield M.M., 554 Motzke I., Nault B.A., Otieno M., Petersen J., Pisanty G., Potts S.G., Rader R., Ricketts T.H., Rundlöf 555 M., Seymour C.L., Schüepp C., Szentgyörgyi H., Taki H., Tscharntke T., Vergara C.H., Viana B.F., 556 Wanger T.C., Westphal C., Williams N. and Klein A.M., 2013. Wild Pollinators Enhance Fruit Set of 557 Crops Regardless of Honey Bee Abundance. Science 339, 1608-1611. 
Greenleaf, S. and Kremen, C. (2006) Wild Bees Enhance Honey bees Pollination of Hybrid Sunflower; Proceedings of the National Academy of Sciences of The United States of America 103, (37), 1389013895

Hanley N., J.F. Shorgen and B. White (2007) Environmental Economics in Theory and Practice (2 ${ }^{\text {nd }}$ Edition), Palgrave Macmillan, Hampshire, New York

Hensher D.A. (2006) How Do Respondents Process Stated Choice Experiments? Attribute Consideration under Varying Information Load; Journal of Applied Econometrics 21, 861-878

Hensher D.A. (2010) Hypothetical bias, choice experiments and willingness to pay; Transportation Research Part B 44, 735-752

Hynes S., Campbell D. and Howley P. (2010) A Holistic vs. an Attribute-based Approach to AgriEnvironmental Policy Valuation: Do Welfare Estimates Differ?; Journal of Agricultural Economics 62, 305-329

Ivehammar P. (2009) The Payment Vehicle Used in CV Studies of Environmental Goods Does Matter; Journal of Agricultural and Resource Economics 34, 450-463

Junge X., Lindemann-Matthies P., Hunziker M. and Schüpbach B. (2011) Aesthetic preferences of non-farmers and farmers for different land-use types and proportions of ecological compensation areas in the Swiss lowlands; Biological Conservation 144, 1430-1440

Kadoya T., Ishii H.S., Reina H., Shin-ichi S. and Izumi W. (2009) Using Monitoring Data Gathered by Volunteers to Predict the Potential Distribution of the invasive alien Bumblebee Bombus terrestris; Biological Conservation 142, 1011-1017

Kehlbacher, A., Balcombe, K. and Bennett, R. (2013) Stated attribute non-attendance in successive choice experiments. Journal of Agricultural Economics In Press

Kellert S. (1996) The Value of Life - Biological Diversity and Human Life; Island Press, Washington

Klein, A. M., Vaissiere, B. E., Cane, J. H., Steffan-Dewenter, I., Cunningham, S. A., Kremen, C., Tscharntke, T. (2007) Importance of Pollinators in Changing Landscapes for World Crops; Proceedings of the Royal Society B-Biological Science 274, 303-313

Kwak M.M. (1997) Public Bumblebee Survey in the Netherlands in 1994 and 1995; Acta Horticulturae 437, 413-417

Lindemann-Matthies P., Junge X. and Matthies D. (2010) The influence of plant diversity on people's perception and aesthetic appreciation of grassland vegetation; Biological Conservation 143 195-202

MacKeron G.J., Egerton C., Gaskell C., Parpia A. and Mourato S. (2009) Willingness to Pay for Carbon Offset Certification and Co-Benefits among (high-)Flying Young Adults in the UK; Energy Policy 37, 1372-1381

Meyhoff J. and Liebe U. (2009) Status Quo Effect in Choice Experiments: Empirical Evidence on Attitudes and Choice Task Complexity; Land Economics 85, 515-528 
594 Quantifying the Value of Ecosystem Services: A Case Study of Honeybee Pollination in the UK;

595 Contributed Paper for the 12th Annual BIOECON Conference

596 Natural England (2009) Experiencing Landscapes: capturing the cultural services and experiential 597 qualities of landscape; http://naturalengland.etraderstores.com/NaturalEnglandShop/NECRO24

598 Ollerton J., Winfree R., Tarrant S., (2011) How many flowering plants are pollinated by animals? 599 Oikos 120, 321-326.

600 ONS (2011) Labour Market Statistics November 2011; http://ons.gov.uk/ons/dcp171766 241671.pdf

601 Osborne J.L., Martin A.P., Shortall C.R., Todd A.D., Goulson D., Knight M.I., Hale R.J. and Sanderson

602 R.A. (2008) Quantifying and comparing bumblebee nest densities in gardens and countryside 603 habitats; Journal of Applied Ecology 45, 784-792

604 Potts S.G., Biesmeijer J.C., Kremen C., Neumann P., Schweiger O. and Kunin W.E. (2010) Global

605 Pollinator Declines; Trends, Impacts and Drivers; Trends in Ecology and Evolution 25, 345-353

606 Rolfe J. and Bennett J. (2009) The impact of offering two versus three alternatives in choice 607 modelling experiments; Ecological Economics 68, 1140-1148

608 Samnegård U., Presson A.P. and Smith H.G. (2011) Gardens benefit bees and enhance pollination in 609 intensively managed farmland; Biological Conservation 144, 2602-2606

610 Sarrantonio M. (2007) Managing Cover Crops Profitably ( $3^{\text {rd }}$ Edition); Sustainable Agricultural

611 Networks, Boltsville MD

612 Scarpa R., Gilbride T.J., Campbell D. and Hensher D.A. (2009) Modelling attribute non-attendance in 613 choice experiments for rural landscape valuation; European Review of Agricultural Economics 36, $614 \quad 151-174$

615 Scarpa R., Thiene M. and Hensher D.A. (2010) Monitoring Choice Task Attribute Attendance in 616 Nonmarket Valuation of Multiple Park Management Services: Does It Matter?; Land Economics 86, $617 \quad 817-839$

618 Smith P., Ashmore M., Black H., Burgess P., Evans C., Hails R., Potts S.G., Quine T., Thomson A., 619 (2011) UK National Ecosystem Assessment - Chapter 14: Regulating Services. UNEP-WCMC, 620 Cambridge.

621 Soini K. and Aakkula J. (2007) Framing the biodiversity of agricultural landscape: The essence of local 622 conceptions and constructions; Land Use Policy 24, 311-321

623 Spash C., Urama K., Burton R., Kenyon R., Shannon P. and Hill G. (2009) Motives behind willingness 624 to pay for improving biodiversity in a water ecosystem: Economics, ethics and social psychology; 625 Ecological Economics 68, 955-964

626 Train K. (2003) Discreet Choice Modelling With Simulations ( $3^{\text {rd }}$ Edition) Cambridge University Press, 627 Cambridge 
628 Winfree R., Gross B. J. and Kremen C. (2011) Valuing pollination services to agriculture; Ecological

629 Economics $71,80-88$

630 Zander K.K. and Straton A. (2010) An economic assessment of the value of tropical river ecosystem

631 services: Heterogeneous preferences among Aboriginal and non-Aboriginal Australians; Ecological

632 Economics 69, 2417-2426

\section{Acknowledgements}

634 The authors thank Nick Hanley, Liz Robinson and Mike Christie for their helpful comments and

635 feedback on earlier drafts of this paper. This research was funded received funding from the

636 European Community's Seventh Framework Programme (FP7/2007-2013) under grant agreement no

637 244090, STEP Project (Status and Trends of European Pollinators: www.step-project.net). 